Marcum, C.D., Ricketts, M.L., \& Higgins, G.E. (2010). Assessing sex experiences of online victimization: An examination of adolescent online behaviors utilizing Routine Activity Theory. Criminal Justice Review, 35(4): 412437. Published by Sage (ISSN: 0734-0168). doi:10.1177/0734016809360331

\title{
Assessing Sex Experiences of Online Victimization: An Examination of Adolescent Online Behaviors Using Routine Activity Theory
}

\author{
Catherine D. Marcum, Melissa L. Ricketts, and George E. Higgins
}

\begin{abstract}
The purpose of this study was to investigate the differences in online victimization between genders, through variables representing the three constructs of routine activity theory. A survey was administered to 100-level courses at a mid-sized university in the northeast, which questioned respondent on their Internet behaviors and experiences during the high school senior and college freshman time period. The findings of the study indicated that participating in behaviors that increased exposure to motivated offenders and target suitability in turn increased the likelihood of victimization for both genders. Conversely, taking protective measures to improve capable guardianship was shown to be the least effective measure, as it did not decrease the likelihood of victimization. This research provides a significant contribution to the literature as there are few explanatory studies that attempt to identify causal reasoning for this behavior.
\end{abstract}




\section{INTRODUCTION}

The technological advancement of what was termed "ARPANET" quickly evolved into what we now refer to as the Internet (Leiner et al., 2003). With the demand in popularity for technology, the Internet experienced the perfect environment to thrive and soon began to do so. The goal of the Internet was to become a collection of communities that provided useful information to its users. By the early 1990s, use of the Internet became a familiar facet in businesses and homes and by the year 2001, over half of the U.S. population included regular users of the Internet (Sanger, Long, Ritzman, Stofter, \& Davis, 2004). Today's Internet now allows people to shop, make travel arrangements, buy stocks, and most importantly, communicate.

Of the millions of people who go online daily, adolescent Internet use is increasing faster than any other age group (Jones \& Fox, 2009; Wolak, Mitchell, \& Finkelhor, 2006). Although awareness is growing, Medaris and Girouard (2002) asserted that this age bracket is not fully informed of the dangers online and the possible consequences of providing personal information to Internet predators.

Several studies of Internet use by adolescents have found that increasing numbers of young people are experiencing the following types of victimization while using computer-mediated communication (CMC) methods: unwanted exposure to sexual material, sexual solicitation, and unwanted nonsexual harassment (Marcum, in press; Mitchell, Finkelhor, \& Wolak, 2003, 2007; O'Connell, Barrow, \& Sange, 2002; Quayle \& Taylor, 2003; Sanger et al., 2004; Wolak, Mitchell, \& Finkelhor, 2002, 2003, 2004, 2006, 2007; Ybarra, Mitchell, Finkelhor, \& Wolak, 2007).

According to routine activity theory, three elements must be present for a crime to occur: exposure to motivated offenders, a suitable target, and a lack of capable guardianship (Cohen \& Felson, 1979). This assertion has been supported in multiple studies of various types of criminal activity (Arnold, Keane, \& Baron, 2005; Gaetz, 2004; Mustaine \& Tewksbury, 1999; Roncek \& Bell, 1981; Schreck \& Fisher, 2004; Spano \& Nagy, 2005; Tewksbury \& Mustaine, 2000), but studies using routine activity theory are lacking regarding the explanation of cyber crime and victimization, especially in the area of adolescents. The purpose of this study was to investigate the differences, if any, in online victimization between male and female high school seniors and college freshmen using variables representing the three constructs of routine activity theory.

\section{ADOLESCENT INTERNET USE AND VICTIMIZATION}

Past empirical research indicated that adolescents and younger adults constitute one of the fastest growing Internet user populations (Addison, 2001; Lenhart, Rainie, \& Lewis, 2001; Medaris \& Girouard, 2002; Nie \& Ebring, 2000; Rainie, 2006). According to Pew Research polls, over 80\% of adolescents had access to the Internet at their home (Jones \& Fox, 2009). Hunley, Evans, Delgado-Hachey, Krise, Rich, and Schell (2005) found that both males and females spent similar amounts of time using the Internet. In regard to the purpose of Internet use, teenagers and those considered

Generation Y-ers are more likely use the Internet for entertainment and communication purposes. Moreover, $75 \%$ of $18-24$ year olds actively use a social networking Web site (Greenwood, 2009). The various mediums of communication available on the Internet have been a contributing factor to increased Internet use by providing effortless means of socializing (Clemmitt, 2006; Kirkpatrick, 2006; Lamb \& Johnson, 2006; Rosen, 2006; Simon, 2006; Stuzman, 2006). Apparently, there is no significant difference between sexes in regard to their main purpose of Internet use as Lin and $\mathrm{Yu}(2008)$ found that both males and females actively used the Internet for socialization purposes.

The mediums of communication available on the Internet, often referred to collectively as social technology (Lamb \& Johnson, 2006), have enabled people of all ages to expand their social circles and improve their ability to communicate with friends and family in an inexpensive manner (Roberts, Foeher, Rideout, \& Brodie, 1999). Social technology generally refers to CMC devices that 
connect people for personal and professional information sharing. The use of CMC methods allows for ease in the workplace, educational setting, or home to communicate effortlessly with others (Simon, 2006). Although there are numerous ways to communicate and socialize with CMCs, this study will focus on the following mediums: chat rooms, instant messaging, E-mail, and social networking Web sites. Unfortunately, along with the beneficial use of these CMC methods comes the increased possibility of online victimization.

A direct example comes from evidence derived from the Youth Internet Safety Survey (YISS), a nationally representative study (sponsored by the National Center for Missing and Exploited Children) of 1,501 adolescents, falling in the age range of 10-17 years old, who participated in regular use of the Internet. The two administrations of the YISS (the first [YISS-1] occurred between August 1999 and February 2000 and the second [YISS-2] between March and June 2005) showed an increase in Internet victimization between the two time periods. First, the proportion of youth who reported online harassment grew from $6 \%$ to $9 \%$. Despite the increased usage of filtering and blocking software by parents ( $55 \%$ of parents in the second study reported the use of this software), unwanted exposure to sexual material increased by $9 \%$. In addition, of the unwanted exposure to sexual material, the number of youth who reported distressing reactions to the material grew $3 \%$ since the first survey. A larger amount percentage of youth received unwanted sexual solicitation compared to the first survey (13\% in 2001 vs. 19\% in 2006). However, aggressive solicitations, which included attempts to contact the youth offline, did not increase (Wolak et al., 2006).

A more recent study used data from the YISS-2 to identify online behaviors that increase the likelihood of online victimization. Youth were found to participate in several types of risky behaviors online, such as disclosure of personal information, talking about sex with someone known only online, and harassing others online. Of these risky behaviors, talking about sex with unknown people online and meeting people online in multiple ways were found to produce significantly higher odds of online interpersonal victimization. However, posting or sending personal information online by itself was not significantly associated with increased odds of online interpersonal victimization (Ybarra et al., 2007).

More recent empirical studies examined the effect of different forms of protective measures on adolescent online victimization. Marcum (IN PRESS) found that the installation of filtering and blocking software had no effect on the exposure to inappropriate materials and behaviors, as well as online victimization for high school seniors and college freshmen. Lwin, Stanaland, and Miyazaki (2008) further explored protective measures through a quasiexperimental study of 10-17 year olds in regard to their experiences with Internet monitoring and mediation by parents. They found that active Internet behavior monitoring by parents decreased the likelihood of participation in risky behaviors online, as well as exposure to inappropriate materials. However, Lwin et al. (2008) noted that the effectiveness of active monitoring decreased the older than adolescent became, which may be a foreshadowing of the results found in the current study considering the age of the sample.

Although most studies have involved the investigation of persons younger than 18 years, as they are the population that experiences harassment and victimization more than any other age group, adults also are using the forms of CMCs used by the younger crowd (Harris Interactive, 2001). Undergraduates at the University of New Hampshire (n 1/4 339) were surveyed with regard to their experiences with online harassment (Finn, 2004). Approximately $60 \%$ reported receiving unwanted pornography, and 10\% reported receiving threatening instant messages or E-mails. Only $7 \%$ of the students actually reported the harassment to the authorities (Finn, 2004). Moreover, Mitchell, Finkelhor, and Becker-Blease (2007) surveyed a random sample of adult professionals on their experiences regarding various types of victimization online and offline. Of a sample of 929 adult respondents, $7 \%$ reported online harassment, $5 \%$ reported sexual exploitation and abuse, and $5 \%$ experienced fraud or deception. Although the adults in the sample had a notable amount of victimization, it was still comparably lower than victimization rates experienced by younger users who presumably participate in more risky online behaviors. 
Although studies examining separate online victimization experiences of sexes are limited, those available shows that findings have been mixed. Mottram and Fleming (2009) found that male adults are more likely to experience a higher degree of problems on the Internet. However, Wells and Mitchell (2007) found that female youth were more likely to experience sexual exploitation online. Due to the lack of uniformity in the findings, further research is needed investigating potential differences between the sexes regarding Internet victimization.

The majority of studies examining Internet use and victimization are descriptive in nature, and therefore there is a lack of rigorous research that indicates what online behaviors may increase the likelihood of victimization. Furthermore, the literature is weak in regard to studies that use a strong theoretical basis to examine these online outcomes. Based on the assertion by Roncek and Maier (1991) that routine activity theory is excellent for use in the examination of predatory or exploitative crimes (the type of deviant behavior examined in this study), this theory will be used to investigate online behaviors and victimization in the study's sample of college freshmen.

\section{ROUTINE ACTIVITY THEORY}

The work of Cohen and Felson (1979) was preceded by the work of Hindelang, Gottfredson, and Garofalo (1978), as well as Amos Hawley (1950). Hindelang et al. developed what is commonly termed "lifestyle/exposure theory," which was based on correlation between lifestyle choices and victimization. They asserted that the variance in victimization risk is related to differences in lifestyle choices. Lifestyle choices encompass the daily activities of a person's life, such as work, school, and extracurricular activities. Choices made by individuals influence their exposure to different persons and places, as well as deviant behaviors, which increases their own risk of victimization (Hindelang et al., 1978). Routine activity theory is somewhat similar to lifestyle/exposure theory (Messner \& Tardiff, 1985). According to Brantingham and Brantingham (1981), Cohen and Felson sought to expand and improve on the work of Hindelang et al. by incorporating ecological concepts, specifically Hawley's (1950) components of temporal organization: rhythm, tempo, and timing. Rhythm is the regularity with which events occur. Tempo is the number of events that occur per unit of time. Finally, timing is the duration and recurrence of the events. According to Cohen and Felson, the inclusion of these three components improves the explanation of how and why criminal activity is performed.

The current version of routine activity theory asserts that there are three components necessary in a situation for a crime to occur: a suitable target, a lack of a capable guardian, and a motivated offender (Cohen \& Felson, 1979). Moreover, crime is not a random occurrence, but rather, follows regular patterns that require these three components. According to Cohen and Felson (1979), target suitability is based on a person's availability as a victim, as well as his or her attractiveness to the offender. A person who is available for victimization is someone who has not taken certain precautions to protect themselves. Guardianship is the ability of persons and objects to prevent a crime from occurring (Cohen \& Felson, 1979; Garofalo \& Clark, 1992; Meier \& Miethe, 1993; Tseloni, Wittebrood, Farrell, \& Pease, 2004) and can take two forms: social and physical. Finally, a motivated offender is a person who is willing to commit a crime when opportunities are presented through the presence and absence of the other two components (Cohen \& Felson, 1979; Mustaine \& Tewksbury, 2002). In other words, the theory asserts that if a motivated offender is presented with a suitable target that is not properly guarded against victimization, a crime is likely to occur.

Based on an examination of the relevant literature, routine activity theory has been supported on both the macro- and micro-levels (Arnold et al., 2005; Cao \& Maume, 1993; Gaetz, 2004; Mustaine \& Tewksbury, 1999; Roncek \& Bell, 1981; Roncek \& Maier, 1991; Schreck \& Fisher, 2004; Spano \& Nagy, 2005; Tewksbury \& Mustaine, 2000). Although not as plentiful as micro-level research, macro-level investigations of routine activity theory have revealed empirical support for the components of the theory. In particular, lack of guardianship in areas with large amounts of traffic from nonresidents having no ties to the area was shown to produce a significant effect on crime rates 
in neighborhoods (LaGrange 1999; Roncek \& Bell, 1981; Roncek \& Maier, 1991). Moreover, the lack of guardianship and risky lifestyles of city residents have a significant relationship with victimization (Cao \& Maume, 1993; Forde \& Kennedy, 1997). Finally, an examination of countries in different continents revealed support for the theory, by demonstrating how not only a lack of guardianship, but crossing paths with a motivated offender as a suitable target, increases the likelihood of victimization (Tseloni et al., 2004).

Micro-level studies use individual-level data, which allow for analysis of factors that specifically apply to individuals, rather than across large groups. Literature on offending behavior indicated unstructured peer interaction and lack of parental supervision and connection reflected a lack of guardianship that was a significant predictor of criminal offending (Bernburg \& Thorlindsson, 2001; Felson, 1986; Sasse, 2005; Schreck \& Fisher, 2004). Personal and property crime victimization studies suggested a person's routine activities, such as participating in leisure activities away from the home and other lifestyle choices, significantly increase the likelihood of victimization (Arnold et al., 2005; Cohen \& Cantor, 1980; Cohen \& Felson, 1981; Gaetz, 2004; LaGrange, 1994; Mustaine \& Tewksbury, 1999; Spano \& Nagy, 2005; Tewksbury \& Mustaine, 2000). Domain-specific models were noted to better explain routine activities in a specific environment (Mustaine \& Tewksbury, 1999; Madriz, 1996; Wang, 2002). Finally, current studies revealed that drug and alcohol consumption is a significant predictor of sexual victimization of females (Mustaine \& Tewksbury, 2002; Schwartz, et al., 2001).

These same theoretical concepts of routine activity theory are applied to the measurement of online victimization in this study. Although there is still a small amount of literature available applying a theoretical explanation for online victimization, researchers such as Holt and Bossler (2009) found support for the use of routine activity theory in explaining this type of criminality. For this particular study, in regard to exposure to motivated offenders, an individual that spendsmore time (e.g., hours) online is more likely to be victim because they are exposed to other users on the Internet for a more extended period of time. Furthermore, the more activities that the individuals perform are more likely to expose them to the possibility of online victimization, because they are creating a better opportunity to be tracked and that their activities be maliciously followed while on the Internet. Target suitability is applied by examining the types and amount of personal information provided online, which makes a respondent more attractive to motivated offenders. The more personal information provided increases a person's target suitability. Finally, lack of guardianship measures are represented by monitored Internet use and protective measures used online. Utilization of one or more of these guardianship techniques would decrease the victimization ability by a motivated offender.

\section{THE CURRENT STUDY}

Early tests of routine activity theory, which often is used to examine different types of victimization, focused on the importance of the environment as a vital component of interaction between criminal offenders and victims (Cohen \& Felson, 1979). This is particularly relevant to the current research, as the environment, cyberspace, is a necessary factor that must be present to both participate in online activities and become a victim of harassment or other online crime. Cyberspace, which thrives on the possibilities of the unknown, also provides the opportunity for engaging in activities without the presence of a capable guardian. This is true for both the offender and the victim, as both parties potentially can participate in deviant behaviors without much guardianship being present (Jones, 1999). According to Felson (1986), a lack of behavioral controls encourages willingness to participate in criminal activity, and motivated offenders will place themselves in areas that have an abundance of suitable targets. As there are very few published studies that examine the potential differences between male and female Internet experiences, the present study will contribute to the literature by examining how the routine activities of male and female adolescents affect their likelihood of online victimization. 


\section{METHOD Sample}

The population for the current research included all undergraduate students enrolled in 100-level course at a mid-sized university in the northeast during the spring 2008 academic term.1 To obtain a representative sample of freshmen, 2 a sampling frame of all 100-level courses potentially available to freshman at the main campus in spring 2008 , along with the respective sections available for each course was used. Course sections were randomly selected and permission was requested from the professor of the course to administer the survey to the class of students. The surveys were distributed at the beginning of the spring semester, when attendance is generally the highest. This process continued until a sample of 850 surveys was collected for analysis.3 Of the 850 surveys collected, 106 were discarded either because they were not completed or the respondent refused to participate in the study. Therefore, a total sample of 744 respondents was used for this analysis.

\section{RESEARCH DESIGN Measures}

The measures for the study include the independent variables (exposure to motivated offenders, target suitability, and lack of capable guardianship), dependent variables (unwanted sexually explicit material, unwanted nonsexual harassment, and unwanted sexual solicitation), and control measures (i.e., sex, age, and race). Questions in the survey were developed based on previous surveys of online victimization, as well as how the authors perceived would be the best measurement of routine activity theory regarding this specific type of victimization. Respondents were questioned about their Internet behaviors, activities, and experiences with online victimization during the high school senior and college freshman time periods.4 See Table A1 for a complete listing of the frequencies of all the independent variables.5

Exposure to motivated offenders. Researchers have shown that individuals that spend more time outside their homes are exposed to more crime and potential victimization than individuals that spend more time at home (Arnold et al., 2005; Tewksbury \& Mustaine, 2000). One way to leave the protection of home and become exposed to potential victimization is to go onto the Internet. Thus, one form of exposure to potential victimization is going online. The measure of exposure to motivated offenders in this study was operationalized in two sets of questions: general Internet use and types of activities. General Internet use was operationalized via the following question: "How many hours per week did/do you typically spend on the Internet?" Measurement of these questions was open ended. Higher scores for this question indicated more general Internet use that increases the potential exposure to motivated offenders.

Types of activities were operationalized using the following set of questions: "Did/do you use E-mail?" "If you answered yes, how many hours per week did/do you spend using E-mail?" "Did/ do you use instant messaging?" "If you answered yes, how many hours per week did/do you spend using instant messaging?" "Did/do you use chat rooms?" "If you answered yes, how many hours per week did/do you spend using chat rooms?" "Did/do you use social networking Web sites?" "If you answered yes, how many hours per week did/do you spend using social networking Web sites?" The hours per week spent using the various methods of CMC were used in the model to measure exposure. To produce a more normal distribution for these items and avoid a severe positive skew in the original variables, all extreme values in the tails were collapsed to create a recoded variable. This set of items addresses the issues that different activities may expose the student to motivated offenders.

Target suitability. Past research has indicated that individualswho increase their likelihood of coming into contact with motivated offenders through exposure of their personal lives, whether with some form of contact or leaving their possessions unattended, increase target suitability (Gaetz, 2004; Schreck \& Fisher, 2004; Spando \& Nagy, 2005). This can occur online through the exposure of personal information. 
To capture target suitability (i.e., activities thatmake the studentmore attractive tomotivated offenders), the students were asked to provide responses to the following series of questions: "Was/is your social networking Web site marked 'private,' so only designated friends could/can see your profile?" "What types of information did/do you post on your social networking Web site?" Respondents were able to choose the following types of information: age, gender, descriptive characteristics, picture, telephone number, school information, extracurricular activities, goals, sexual information, emotional distresses, family conflicts, and other.6 "Did/do you communicate with people online, via E-mail, instant messaging, or chat rooms, that you had/have nevermet in person?"Dichotomous variables were created based on a no/yes response. "Did/do you voluntarily give personal information to a person you met online?" As for the previous measurement, dichotomous variables were created based on a no/yes response. "What types of information did/do you provide to an online contact?" Answer choices were the same types of information as could be provided on a social networking Web site.7

Lack of capable guardianship. Guardianship measures can appear in many different forms, whether it is increased lighting in a dark alley, locks on doors, or privatization of social networking Web sites. However, despite the measures taken, multiple studies have found that increasing guardianship decreases the likelihood of victimization (Arnold et al., 2005; Schreck \& Fisher, 2004; Wang, 2002). To capture the lack of capable guardianship (i.e., the amount of monitoring experienced by respondent as high school seniors and college freshmen at the university, as well as self-protective measures), five items were used. The first item was "where did/do you most often use a computer?"

Respondents were provided with responses that included various rooms in their homes, school computer lab, and a friend's home. The second item was "Please mark any of the parties listed that were/ are typically in the same room with you when you used/use a computer?" Respondents were instructed to mark all that applied and analyzed separately in the model to see whether having a particular party in the room affected the likelihood of victimization. Responses included parent, friend, teacher/counselor, sibling, someone else, and no one. The third item was "Please mark all of the restrictions you had/have from your parent/guardian while using the Internet?" Respondents were instructed to mark all that applied and analyzed separately in the model to see whether having a particular restriction affected the likelihood of victimization. Responses included time spent online, viewing of adult Web sites, use of CMCs, other, and no restrictions. The fourth item was "To your knowledge, did/do your parent/guardian or another adult actively monitor your Internet use by regularly checking the Web sites you visited?" Variables were created based on a yes, no, or unsure response. The fifth item was "To your knowledge, was/is any type of blocking or filtering software on the computers you typically used/use to protect you from unwanted materials?" Variables were created based on a yes, no, or unsure response.

Dependent measures. Three dependentmeasureswere examined in this particular study.Respondents were asked whether, during their high school senior and college freshman year, they had received the following from a person online: sexually explicit material (e.g., pornography), nonsexual harassment (e.g., unwanted E-mails, instant messages), and sexual solicitation (e.g., request for either online or offline sexual interaction). The dependent measures included requests and materials that were purposely sent by another person, not automatic Internet responses such as pop-up ads. Dichotomous variables were created based on a no/yes response. SeeTableA2 for a complete list of the frequencies and descriptive statistics for the dependent variables.

Control measures. Four measures were used as controls in this study. We controlled for sex. Students indicated their racial or ethnic group. The students indicated their age with an open-ended item: "How old are you?" Finally, current living situation was indicated through a variety of choices, such as parent's home, dormitory, or rented apartment/house. See Table A3 for a complete list of the frequencies for the control variables.

\section{HYPOTHESES}

The following hypotheses were formulated based on the purpose of the study and were evaluated based on the results of the analysis: 
Hypothesis 1: Adolescents who spend more time on the Internet using modes of CMC are more likely to be victimized online and form relationships with online contacts.

Hypothesis 2: Adolescents who provide personal information to online contacts are more likely to be victimized online.

Hypothesis 3: Adolescents who use protective software are less likely to be victimized online.

\begin{abstract}
ANALYSIS
Data obtained through administration of the survey were analyzed in different manners through various techniques. Because the dependent variables initially were measured as a dichotomy, logistic regression models were used to assess relationships between the independent variables and the likelihood of victimization.8 Due to the large number of independent variables measured in this study, stepwise logistic regression was used to determine the appropriate variables to assess in the models. 9 In multivariate analysis, some variables can have a statistically significant effect only when another variable is controlled, which is called a suppressor effect (Agresti \& Finlay 1997). As a result, backward elimination was selected as the method of stepwise regression, whereby all possible variables are initially contained in the model, and there is less risk of ruling out variables involved in suppressor effects (Menard, 2007).
\end{abstract}

Another step taken to enhance the discovery of potential relationships was to relax the $p<.05$ criterion for retention of variables in the models. Bendel and Afifi (1977) asserted that $p<.05$ is too low and further recommended that the criterion for retention in the stepwise model be set at .15 or .20, so important variables are not excluded. The criterion for retention of variables in this study was set at .20, to better reveal any possible statistically significant relationships. Furthermore, linear probability models first were used to identify any possible problems with multicollinearity, through the use of tolerance statistics and variance inflation factors.

\title{
RESULTS
}

High School Senior Time Period

As described previously, stepwise regression with backward elimination was used in the analysis. Independent variables measuring the theoretical construct of exposure to motivated offenders were initially inserted in the model to examine their effects on the dependent variables, and then only the significant measures were retained for the next step, which involved insertion of independent variables measuring target suitability. This process continued with the lack of capable guardianship and control variables until full models including all retained significant variables from each theoretical construct was included. Only the full models are presented in the corresponding tables.

Table 1 presents the logistic regression estimates for males and females for the dependent variable "receipt of sexually explicit material" during the high school senior time period. Variables retained at the .20 level were shown to explain $12.5-17.6 \%$ of the variation in the dependent variable for males, but only $9.5-14.0 \%$ for females. Males and females had one common statistically significant predictor. Use of chat rooms (Chat) increased the likelihood of victimization for both male $(b=.072, p<.05)$ and female $(b=.056, p<.05)$ respondents, therefore indicating that use of this particular method of CMC was risky despite a respondent's sex. 
Table I. Logistic Regression Estimates for the Dependent Variable Receipt Sexually Explicit Material During the High School Senior Time Period $(N=744)$

\begin{tabular}{|c|c|c|c|c|c|}
\hline \multirow[b]{2}{*}{ Variable } & \multicolumn{2}{|c|}{ Male Model $(N=325)$} & \multirow[b]{2}{*}{ Variable } & \multicolumn{2}{|c|}{ Female Model $(\mathrm{N}=4 \mid 5)$} \\
\hline & $B(S E)$ & $\operatorname{Exp}(B)$ & & $B(S E)$ & $\operatorname{Exp}(B)$ \\
\hline Chat & $.072(.033)$ & $1.075 *$ & E-mail & $.231(.080)$ & $1.25 \%$ \\
\hline Travel & $.589(.292)$ & $1.803 *$ & $\mathbb{I M}$ & $-.045(.021)$ & .956 \\
\hline Design & $.442(.332)$ & 1.556 & Chat & $.056(.027)$ & $1.058 *$ \\
\hline Facebook & $.571(.285)$ & 1.770 & Travel & $-.374(.272)$ & .688 \\
\hline ParlnRm & $.660(.280)$ & 1.934 & Shop & $.481(.262)$ & 1.617 \\
\hline TeachlnRm & $.738(.374)$ & $2.092 *$ & Other & $.607(.376)$ & 1.835 \\
\hline RestrictTime & $.522(.357)$ & 1.686 & Info & $.086(.050)$ & 1.089 \\
\hline DKFiltSoft & $1.036(.446)$ & $2.817 *$ & Comm & $.628(.271)$ & 1.873 \\
\hline Age & $.134(.085)$ & 1.143 & Constant & $-1.974(.294)$ & $.139 \% \%$ \\
\hline-2 Log-likelihood & & 347.541 & -2 Log-likelihood & 430.176 & \\
\hline Model Chi-square & & $42.181^{* 10 *}$ & Model Chi-square & $41.442 \%$ & \\
\hline Cox and Snell $R^{2}$ & & .125 & Cox and Snell $R^{2}$ & .095 & \\
\hline Nagelkerke $R^{2}$ & & .176 & Nagelkerke $R^{2}$ & .140 & \\
\hline
\end{tabular}

\footnotetext{
$* p<.05$.

*** $p<.01$

Nolok $p<.001$
}

Males and females also had separate significant predictors. For example, males who were unsure whether filtering and blocking software was installed on their computer (DKFiltSoft) were more likely to receive sexual material $(b=1.036, p<.01)$. This could infer that the possibility of unrestricted Internet use for males led them to areas on the Internet that increased this form of victimization. However, female respondents who had an increased use of E-mail (Email) were also more likely to be victimized $(b=.231, p<.01)$. Apparently, this form of socialization increased victimization for females but had no significant effect on male respondents.

Logistic regression estimates for males and females for the dependent variable "receipt of nonsexual harassment" during the high school senior time period are presented in Table 2. Variables retained at the .20 level were shown to explain a respectable $18.3-25.5 \%$ of the variation in the dependent variable for males, but only $11.4-15.5 \%$ for females. As can be seen in the table, males and females shared no statistically significant predictors.

In regard to male respondents, use of instant messaging (IM; $b=.057, p<.05)$ as a method ofCMC increased the likelihood of receipt of nonsexual harassment.Not surprisingly, having no one in the room during Internet use also increased the receipt of nonsexual harassment (NoOneRm; $b=.989, p<.01$ ). Unmonitored Internet use allows a user to participate in more risky behaviors that may lead to victimization without judgment or correction. However, main use of the Internet in areas with higher levels of guardianship, such as the family living room(LivRm; $b=-2.101, p<.05)$ or in the school computer lab (SchLab; $b=-2.331, p<.05$ ), decreased the likelihood of this formof victimization. Females, however, had fewer indicators of victimization. For example, providing personal information on a social networking Website (SNWInfo; $b=.148, p<.01$ ) increased the likelihood of receipt of nonsexual harassment. Again, this is not surprising as target suitability is increased by such personal exposure. 
Table 2. Logistic Regression Estimates for the Dependent Variable Receipt of Nonsexual Harassment During the High School Senior Time Period $(N=744)$

\begin{tabular}{|c|c|c|c|c|c|}
\hline \multirow[b]{2}{*}{ Variable } & \multicolumn{2}{|c|}{ Male Model $(N=325)$} & \multirow[b]{2}{*}{ Variable } & \multicolumn{2}{|c|}{ Female Model $(N=415)$} \\
\hline & $B(S E)$ & $\operatorname{Exp}(B)$ & & $B(S E)$ & $\operatorname{Exp}(B)$ \\
\hline IM & $.057(.025)$ & $1.059 *$ & E-mail & $.110(.073)$ & 1.116 \\
\hline Research & $1.809(1.082)$ & 6.106 & Social & $1.261(.566)$ & $3.250 *$ \\
\hline Travel & $.564(.296)$ & 1.757 & SNWInfo & $.148(.047)$ & $1.160^{* * *}$ \\
\hline Social & $.881(.529)$ & 2.414 & YourBed & $.352(.250)$ & 1.421 \\
\hline Other & $.829(.274)$ & $2.291 *$ & OtherRm & $.551(.289)$ & 1.735 \\
\hline Info & $.088(.050)$ & 1.092 & SchLab & $-1.560(1.082)$ & .210 \\
\hline LivRm & $-2.101(.835)$ & $.122 *$ & OthlnRm & $.769(.338)$ & $2.158 *$ \\
\hline YourBed & $-2.599(.860)$ & $.074 \%$ & RestrictAdult & $-.437(.237)$ & .646 \\
\hline OtherRm & $-1.768(.880)$ & $.171 *$ & RestrictCMC & $1.187(.468)$ & $3.278 *$ \\
\hline SchLab & $-2.331(1.145)$ & $.097 *$ & GPA & $-.168(.112)$ & .845 \\
\hline OthPI & $-2.431(1.458)$ & .088 & Constant & $-2.446(.641)$ & $.087 * 01 \%$ \\
\hline FrilnRm & $.521(.305)$ & 1.684 & & & \\
\hline NoOneRm & $.989(.310)$ & $2.636 \% *$ & & & \\
\hline DKFiltSoft & $.823(.453)$ & 2.278 & & & \\
\hline Age & $.108(.081)$ & 1.114 & & & \\
\hline GPA & $-.222(.111)$ & $.805 *$ & & & \\
\hline-2 Log-likelihood & 336.542 & & -2 Log-likelihood & 494.597 & \\
\hline Model Chi-square & 63.861 * & & Model Chi-square & 49.734 & \\
\hline Cox and Snell $R^{2}$ & .183 & & Cox and Snell $R^{2}$ & .114 & \\
\hline Nagelkerke $R^{2}$ & .255 & & Nagelkerke $R^{2}$ & .155 & \\
\hline
\end{tabular}

Note: $\mathbb{I M}=$ Instant messaging.

$* p<.05$

Nok $p<.01$

*olek $p<.001$

Full logistic regression models for males and females for the dependent variable "receipt of sexual solicitation" during the high school senior time period are presented in Table 3. Here, variables retained at the .20 level were shown to explain a healthy $16.6-33.1 \%$ of the variation in the dependent variable for males, but only $13.1-23.3 \%$ for females. Males and females shared two statistically significant predictors. Both male $[\operatorname{Exp}(B)=1.144]$ and female $[\operatorname{Exp}(B)=1.070]$ respondents who used chat rooms (Chat) and increased their exposure to motivated offenders and those males $[\operatorname{Exp}(B)$ $=1.200]$ and females $[\operatorname{Exp}(B)=1.300]$ who provided personal information to online contacts (ProvidedInfo) and increased their target suitability had a greater likelihood of receipt of sexual solicitation. Conversely, males who had restrictions on viewing adult Web sites decreased their likelihood of victimization (RestrictAdult; $b=-2.093, p<.01$ ), again assumedly because of the increased levels of guardianship.

\section{College Freshman Time Period}

Table 4 presents the logistic regression estimates for males and females for the dependent variable "receipt of sexually explicit material" during the college freshman time period. As with tables associated with the high school senior time period, only full models are presented in the tables associated with the college freshman time period. Variables retained at the .20 level were shown to explain $10.2-17.7 \%$ of the variation in the dependent variable for males and $14.1-26.9 \%$ for females. Males 
and females shared one statistically significant predictor. Having a person designated as "Other" in the room during Internet use increased the likelihood of victimization for both males (OthInRm) $[\operatorname{Exp}(B)=2.225]$ and females $[\operatorname{Exp}(B)=4.720]$. As discussed previously, respondents were asked to note who was in the room with them during Internet use. Choices included friends, family, teachers, and no one. However, there was not an opportunity to specifically choose a boyfriend/girlfriend or a stranger as a person in the room with them during Internet use, and therefore these people would fall under "Other." Both parties decrease capable guardianship, as a romantic partner may encourage you to view Web sites with sexually explicit material, while a stranger would have no effect on your choice to view these sites.

Table 3. Logistic Regression Estimates for the Dependent Variable Receipt Sexual Solicitation During the High School Senior Time Period $(N=744)$

\begin{tabular}{|c|c|c|c|c|c|}
\hline \multirow[b]{2}{*}{ Variable } & \multicolumn{2}{|c|}{ Male Model $(N=325)$} & \multirow[b]{2}{*}{ Variable } & \multicolumn{2}{|c|}{ Female Model $(N=415)$} \\
\hline & $B(S E)$ & $\operatorname{Exp}(B)$ & & $B(S E)$ & $\operatorname{Exp}(B)$ \\
\hline Chat & $.134(.041)$ & $1.144 \%$ & Chat & $.067(.030)$ & $1.070 *$ \\
\hline Social & $2.099(1.130)$ & 8.161 & Travel & $-.744(.350)$ & $.475 *$ \\
\hline Other & $.857(.511)$ & 2.355 & Shop & $.754(.344)$ & $2.126 *$ \\
\hline Providedlnfo & $.183(.065)$ & $1.200 \%$ & Social & $1.966(1.090)$ & 7.140 \\
\hline LivRm & $.884(.490)$ & 2.419 & ProvidedInfo & $.263(.053)$ & $1.300 \%$ \\
\hline OthPI & $2.245(1.053)$ & $9.440^{*}$ & RestrictAdult & $.623(.322)$ & 1.864 \\
\hline ParlnRm & $-.888(.505)$ & .411 & RestrictCMC & $-2.071(1.024)$ & .126 \\
\hline RestrictAdult & $-2.093(.692)$ & $.123^{* \% *}$ & DKFiltSoft & $.728(.387)$ & 2.071 \\
\hline RestrictCMC & $2.142(1.107)$ & 8.519 & Constant & $-7.060(1.960)$ & $.001 * 1 \%$ \\
\hline ActMon & $1.551(.609)$ & $4.716^{*}$ & & & \\
\hline Race & $.294(.134)$ & $1.342 *$ & & & \\
\hline Constant & $-5.072(1.147)$ & .006 \% & & & \\
\hline -2 Log-likelihood & 162.683 & & -2 Log-likelihood & 283.771 & \\
\hline Model Chi-square & $57.317^{* 10 \%}$ & & Model Chi-square & $57.919 \%$ & \\
\hline Cox and Snell $R^{2}$ & .166 & & Cox and Snell $R^{2}$ & .131 & \\
\hline Nagelkerke $R^{2}$ & .331 & & Nagelkerke $R^{2}$ & .233 & \\
\hline
\end{tabular}

$* p<.05$

*** $p<.01$

Ne10\% $p<.001$ 
Table 4. Logistic Regression Estimates for the Dependent Variable Receipt of Sexually Explicit Material During the College Freshman Time Period $(N=744)$

\begin{tabular}{|c|c|c|c|c|c|}
\hline \multirow[b]{2}{*}{ Variable } & \multicolumn{2}{|c|}{ Male Model $(\mathrm{N}=325)$} & \multirow[b]{2}{*}{ Variable } & \multicolumn{2}{|c|}{ Female Model $(N=415)$} \\
\hline & $\mathrm{B}(\mathrm{SE})$ & $\operatorname{Exp}(B)$ & & $B(S E)$ & $\operatorname{Exp}(B)$ \\
\hline Travel & $.610(.338)$ & 1.841 & Email & $.199(.110)$ & 1.221 \\
\hline Design & $1.035(.373)$ & $2.815^{* * *}$ & Research & $-1.315(.773)$ & .269 \\
\hline Social & $-.809(.476)$ & .445 & Other & $.856(.415)$ & 2.355 \\
\hline Friend & $-.460(.343)$ & .631 & Facebook & $-1.688(.558)$ & $.185 * \%$ \\
\hline TeachlnRm & $-1.915(1.101)$ & .147 & SNWInfo & $.279(.103)$ & $1.322 * *$ \\
\hline OthlnRm & $.800(.387)$ & $2.225^{*}$ & Comm & $.967(.356)$ & $2.730 * *$ \\
\hline \multirow[t]{3}{*}{ Constant } & $-1.705(.506)$ & $.182 \%$ & Friend & $-.600(.354)$ & .549 \\
\hline & & & OthlnRm & $1.552(.364)$ & 4.720 \%) \\
\hline & & & Constant & $-1.915(.885)$ & $.147^{*}$ \\
\hline -2 Log-likelihood & 242.840 & & -2 Log-likelihood & 242.058 & \\
\hline Model Chi-square & $34.572 \%$ & & Model Chi-square & $62.253 \%$ & \\
\hline Cox and Snell $R^{2}$ & .102 & & Cox and Snell $R^{2}$ & .141 & \\
\hline Nagelkerke $R^{2}$ & .177 & & Nagelkerke $R^{2}$ & .269 & \\
\hline
\end{tabular}

$* p<.05$
$* * * 0<.01$
$* 0 * * * 0<.001$

Males and females also had separate significant predictors of the dependent variable. Males who used the Internet for Web site design (Design) had an increased likelihood of victimization ( $b=$ $1.035, p<.01)$. Females who communicated with online contacts (Comm; $b=.967, p<.01$; increased exposure to motivated offenders) or posted personal information on their social networking Web site (SNWInfo; $b=.279, p<.01$; increased target suitability) were more likely to receive sexually explicit materials. 
Table 5. Logistic Regression Estimates for the Dependent Variable Receipt of Nonsexual Harassment During the College Freshman Time Period $(N=744)$

\begin{tabular}{|c|c|c|c|c|c|}
\hline \multirow[b]{2}{*}{ Variable } & \multicolumn{2}{|c|}{ Male Model $(N=325)$} & \multirow[b]{2}{*}{ Variable } & \multicolumn{2}{|c|}{ Female Model $(N=415)$} \\
\hline & $B(S E)$ & $\operatorname{Exp}(B)$ & & $B(S E)$ & $\operatorname{Exp}(B)$ \\
\hline Email & $.165(.118)$ & 1.180 & IntPerWk & $-.029(.017)$ & .971 \\
\hline Shop & $.811(.439)$ & 2.239 & Travel & $.610(.273)$ & $\left.1.84\right|^{*}$ \\
\hline OtherSNW & $1.520(.769)$ & $4.574^{*}$ & Social & $2.130(1.047)$ & $8.412 *$ \\
\hline Age & $.309(.091)$ & $1.362^{* * *}$ & Comm & $.912(.281)$ & $2.489 * \%$ \\
\hline \multirow[t]{6}{*}{ Constant } & $-8.826(1.879)$ & $.000 * 0 \%$ & SNWInfo & $.139(.083)$ & 1.150 \\
\hline & & & RestrictOther & $1.668(1.015)$ & 5.301 \\
\hline & & & NoRestrict & $.768(.633)$ & 2.156 \\
\hline & & & Race & $.167(.093)$ & 1.182 \\
\hline & & & LivingSituation & $.349(.174)$ & $1.418^{*}$ \\
\hline & & & Constant & $-6.043(1.306)$ & .002 \%क⿻ \\
\hline -2 Log-likelihood & 203.514 & & -2 Log-likelihood & 355.635 & \\
\hline Model Chi-square & $25.926 * 1 \%$ & & Model Chi-square & $51.907 \%$ & \\
\hline Cox and Snell $R^{2}$ & .078 & & Cox and Snell $R^{2}$ & .119 & \\
\hline Nagelkerke $R^{2}$ & .152 & & Nagelkerke $R^{2}$ & .189 & \\
\hline
\end{tabular}

$$
\begin{aligned}
& * p<.05 \\
& { }^{* * *} p<.01 \\
& { }_{* 2 * * *} p<.001
\end{aligned}
$$

The logistic regression estimates for males and females for the dependent variable "receipt of nonsexual harassment" during the college freshman time period are presented in Table 5 . The variables retained at the .20 level again were shown to explain only $7.8-15.2 \%$ of the variation in the dependent variable for males and $11.9-18.9 \%$ for females. Males had respondents who used a social networking Web site designated as "Other" (OtherSNW; $b=1.520, p<.05$ ) were more likely to receive nonsexual harassment. We could infer from these findings that social networking Web sites not as popular as MySpace and Facebook, and possibility not monitored as well, increased likelihood of victimization. With regard to females, communicating with others online (Comm; b =.912, $p<$ .01 ) and using the Internet to socialize (Social; $b=2.130, p<.05$ ) were two variables that increased exposure to motivated offenders and in turn, increased the likelihood of receipt of nonsexual harassment. 
Table 6. Logistic Regression Estimates for the Dependent Variable Receipt of Sexual Solicitation During the College Freshman Time Period $(N=744)$

\begin{tabular}{|c|c|c|c|c|c|}
\hline \multirow[b]{2}{*}{ Variable } & \multicolumn{2}{|c|}{ Male Model $(N=325)$} & \multirow[b]{2}{*}{ Variable } & \multicolumn{2}{|c|}{ Female Model $(N=415)$} \\
\hline & $B(S E)$ & $\operatorname{Exp}(B)$ & & $B(S E)$ & $\operatorname{Exp}(B)$ \\
\hline IntPerWk & $-.062(.03 \mathrm{I})$ & $.940 *$ & IM & $.130(.057)$ & $1.139 *$ \\
\hline Email & $.301(.146)$ & $1.351^{*}$ & Chat & $.744(.405)$ & 2.104 \\
\hline Other & $.727(.515)$ & 2.070 & Comm & $.851(.491)$ & 2.342 \\
\hline Comm & $1.271(.523)$ & $3.564^{*}$ & SNWInfo & $.290(.142)$ & $1.336 *$ \\
\hline OthlnRm & $1.165(.474)$ & $3.206 *$ & Age & $.210(.079)$ & $1.234 *$ \\
\hline Race & $.257(.135)$ & 1.293 & Constant & & \\
\hline LivingSituation & $.403(.238)$ & 1.496 & & & \\
\hline Constant & $-4.176(.967)$ & $.015 \% *$ & & & \\
\hline -2 Log-likelihood & 145.503 & & -2 Log-likelihood & 151.051 & \\
\hline Model Chi-square & $29.264 * *$ & & Model Chi-square & $26.260^{\mathrm{k} * \mathrm{k}}$ & \\
\hline Cox and Snell $R^{2}$ & .089 & & Cox and Snell $R^{2}$ & .062 & \\
\hline Nagelkerke $R^{2}$ & .212 & & Nagelkerke $R^{2}$ & .177 & \\
\hline
\end{tabular}

$* p<.05$

No* $p<.01$

*atol $p<.001$

Table 6 presents the logistic regression estimates for males and females for the dependent variable "receipt of sexual solicitation" during the college freshman time period. Variables retained at the .20 level were shown to explain $8.9-21.2 \%$ of the variation in the dependent variable for males and $6.2-17.7 \%$ for females. Males and females again shared no statistically significant predictors. However, both sexes had variables representing increased exposure to motivated offenders that increased the likelihood of victimization. For males, communicating with others online (Comm; $b=1.271, p<.05)$ increased sexual solicitation, while for females, increased use of instant messaging $(\mathrm{IM} ; \mathrm{b}=.130, \mathrm{p}<.05)$ increased the likelihood of victimization in this manner.

\section{DISCUSSION AND CONCLUSIONS}

Examination of the data showed that behaviors that increased exposure to motivated offenders had a sizeable impact on the likelihood of victimization for both males and females during the high school senior and college freshman time period. This was especially true in regard to use of E-mail, chat rooms, and instant messaging as a method of CMC. This finding was not surprising, as use of these CMCs is increasing in this age group as main modes of communication and youth are spending large amounts of time in these areas. Motivated offenders take notice of the consistent presence of these youth and prey on this predictability. These results, which indicated that exposure to motivated offenders increased a person's likelihood to experience victimization, supported Hypothesis 1 and are also consistent with previous victimization research using routine activity theory. For example, Roncek and Maier (1991) found that increasing the number of cocktail lounges and taverns on a residential block increased the likelihood of crime in a particular area. Furthermore, Tewksbury and Mustaine (2000) found that persons who leave their property unsupervised for longer periods of time, exposing it potential offenders, were more likely to be victimized.

The examination of the data also showed that behaviors that increased target suitability had a large impact on the likelihood of victimization. In fact, participating in behaviors that increased target suitability was shown to have the largest effect on dependent variables during both the high 
school senior and college freshman time period for both males and females. Providing personal information to online contacts affected victimization significantly during the high school senior time period, which in turn supported Hypothesis 2. Moreover, providing personal information on a social networking Web site and communicating with others online increased the likelihood of victimization in the college freshman time period, especially for female respondents. These findings were analogous with previous studies examining victimization through routine activity theory. Multiple studies have found that decreasing a person's target suitability in turn decreases his or her likelihood of becoming a victim of crime (Felson, 1996; Schreck \& Fisher, 2004). For example, Arnold et al. (2005) discovered that if the main activities of respondent involve drinking and other leisure activities, their level of target suitability is increased and in turn, they are more likely to be a victim of crime. Moreover, Wang (2002), during his examination of causal factors associated with bank robberies, determined that banks who presented themselves as suitable targets (i.e., excessive amounts of cash and located close to a major highway) were more likely to be robbed.

Unlike the other two constructs of routine activity theory, protective measures taken during Internet use (measured under the theoretical construct of lack of capable guardianship) had somewhat of an effect on the dependent variables measured in the study. In regard to measures examining lack of capable guardianship, findings from this study indicated that protective software overall had no significant effect on victimization for survey respondents; therefore, Hypothesis 3 was not supported.

This finding was not surprising for the college freshmen time period, as they are generally more independent and not monitored as much at this age. However, the monitoring presence of another person in the room during Internet use and restrictions on Internet use were shown to have significant effects for both male and female high school seniors. As most youth at this age still live at home with their parents or guardians, this finding should also not be surprising as there is more of a monitoring presence during this time period of adolescence.

\section{LIMITATIONS AND FUTURE RESEARCH}

As stated previously, little explanatory research has been performed to examine causal factors that affect the likelihood of online victimization for adolescent; therefore, this study is making a significant contribution to a currently small body of literature. Based on the findings of this study and the remaining need for future research, there are various amendments and suggestions to the present study, which could be implemented to continue the progress of investigating the causal factors of online victimization of youth.

Using a sample of adolescents for this study was chosen because past research has shown that adolescents between the ages of 12 and 17 years old are at high risk for online victimization (Mitchell et al., 2003; O'Connell et al., 2002; Sanger et al., 2004; Wolak et al., 2002, 2006); therefore, the ideal sample for this particular study would include respondents who fall in this age group. Despite this fact, based on a variety of access issues that would have been encountered trying to survey this group, college students who were legally able to participate in research (without parental consent) were chosen. This sample only includes college freshmen and is lacking the inclusion of younger adolescents. Moreover, the sample was not only asked questions about current experiences but also to recall experiences from the high school senior time period. A suggestion for future research would be to survey current high school seniors about their experiences so as to reduce the issue of accurate recall.

Another limitation to the study is in regard to the questions requesting information about the use of CMCs, specifically chat rooms. It is possible that Internet users would be safer from victimization in chat rooms that focus on nonsexual themes (e.g., Star Trek, book clubs) rather than chat rooms that focus on discussions regarding sexual themes. Respondents were only questioned on their general use of chat rooms and not specifically in what types of chat rooms. It would be beneficial in future research to examine the type of chat room used and if that had an effect on online victimization of youth. 


\section{CONCLUSIONS}

The findings of this study indicated that respondents who spent an increased amount of time using the Internet and specific CMCs (in turn exposing their likelihood of encountering a motivated offender) were more likely to be victimized, despite their sex. Nevertheless, it would be futile to attempt to develop prevention programs that encouraged youth to reduce their use of the Internet. Use of the Internet is often necessary for educational purposes, and both males and females use the Internet to socialize and connect with others. In fact, after the administration of the first YISS, Wolak et al. (2002) determined that over half of the youth (55\%) examined reported the use of chat rooms, instant messages, and E-mail to communicate with people they had never met, with the hopes of forming relationships. Rather than encouraging people to stop socializing on the Internet, it would be more effective to educate them on the dangers present online so that they are aware of the potential for victimization.

Adolescents and young adults using the Internet should be educated to not only participate in online communication with people they know and trust but also be wary of to whom they are providing personal information. Many of the respondents in this study reported that they communicated with and provided personal information to people they met online, assumedly with a disregard of the possible consequences of these actions. Past research has shown that there are adolescents who are physically victimized by contacts met online (Kendall, 1998; Tarbox, 2000), as they have pursued offline relationships with these people. If youth limit online communication to people they know, the risk of offline victimization should be lower.

With limited explanatory studies available, which examine the effects of Internet behaviors on online victimization, it is difficult to make concrete conclusions about certain behaviors, as there is little to compare these findings. Yet, greater understanding of the relationship between Internet activities (represented by the three constructs of routine activity theory) and online victimization was gained through the execution of this study. Providing personal information to online contacts and communicating with people met online (variables representing the theoretical construct of target suitability) was the strongest predictor of online victimization. Moreover, use of certain CMCs (variables representing the theoretical construct of exposure to motivated offenders) was also shown to be a significant predictor of certain types of victimization. Conversely, variables representing the third construct of routine activity theory, lack of capable guardianship, were not shown to be overall strong predictors of online victimization of youth.

From the knowledge gained in this study, more effective policy can be developed to educate youth and young adults on protecting themselves while online. Although new technology can be a helpful amenity to its users, it can also be a detriment to their safety and sense of online security. Internet users, particularly of this age group, can continue to enjoy productive online use by taking simple measures to protect themselves and their personal identities.

\section{NOTES}

1. During data collection, surveys also asked respondents questions on their experiences with online victimization in regard to their role as the offender. However, due to the low frequency of respondents who reported offending behaviors, these dependent variables were not included in the analysis.

2. The majority of the literature examined throughout this study pertained to adolescents 12-17 years old, as there is less literature available on the online victimization of adults (18 years and older). However, we feel as if it is important to discuss the literature associated with the younger group as current literature regarding brain development and maturation (Giedd et al., 1999; Steinberg, 2004) asserts that there is not a notable difference between a high school senior and an average college freshman. Therefore, the use of college freshmen for this study appears acceptable when comparing the findings of the current research to past studies of adolescent online behavior, as well as to add to the literature regarding adult victimization. 
3. Estimations of the appropriate ratio of participants to independent variables were considered to assist in the determination of adequate sample size for regression analysis. Stevens (1992) asserted a ratio of 15:1 would be appropriate for a reliable regression equation, while Meyers, Gamst, and Guarino (2005) and Hair, Anderson, Tatham, and Black (1998) indicated a 20: 1 ratio would be appropriate. Based on the number of possible independent variables in this study, these suggestions would encourage a sample of 500-700 subjects.

4. The survey requested information for both the high school senior and college freshman time periods to compare a potential change in behaviors. Considering the change of conditions in their lifestyle (e.g., college freshmen generally have less parental guardianship compared to high school seniors, and therefore their online behavior could increase likelihood of victimization), the authors wanted to investigate whether their online behaviors were different.

5. The authors realize that some readers may consider certain measures of the independent variables incorrectly categorized based on their own opinions of what represents the three constructs of routine activity theory. At the time the survey instrument was created, there were no published studies that used the theory to examine online victimization; therefore, an original instrument based with no past research to base it had to be created. For this particular study, the measures in the survey were categorized based on previous work examining online victimization of youth, as well as what the authors best believed represented each theoretical construct.

6. The total number of types of information provided was combined into one variable (SNWInfo) to be used in logistic regression models, as the researchers believe that providing more types of information indicated a higher likelihood of being a suitable target.

7. The total number of types of information provided was combined into one variable (Providedlnfo) to be used in logistic regression models, as the researchers believe that providing more types of information indicated a higher likelihood of being a suitable target.

8. Z scores were run to assess the logistic parameters between the two time periods. No significant differences between the two time periods for each dependent variables were found.

9. First, variables measuring the theoretical construct of exposure to motivated offenders were inserted in the models to examine their effects on the dependent variables. The next model considered the addition of the effects of the independent variables measuring the theoretical construct of target suitability, while also including retained significant variables measuring exposure to motivated offenders. Third, lack of capable guardianship variables were assessed, in addition to the effects of the other two sets of retained significant independent variables. Finally, full models (i.e., models containing all appropriate variables from all three theoretical constructs) were constructed with the addition of the control variables, while also including the retained significant measures of the three theoretical constructs.

\section{Declaration of Conflicting Interests}

The author(s) declared no conflicts of interest with respect to the authorship and/or publication of this article.

\section{Funding}

The author(s) received no financial support for the research and/or authorship of this article. 


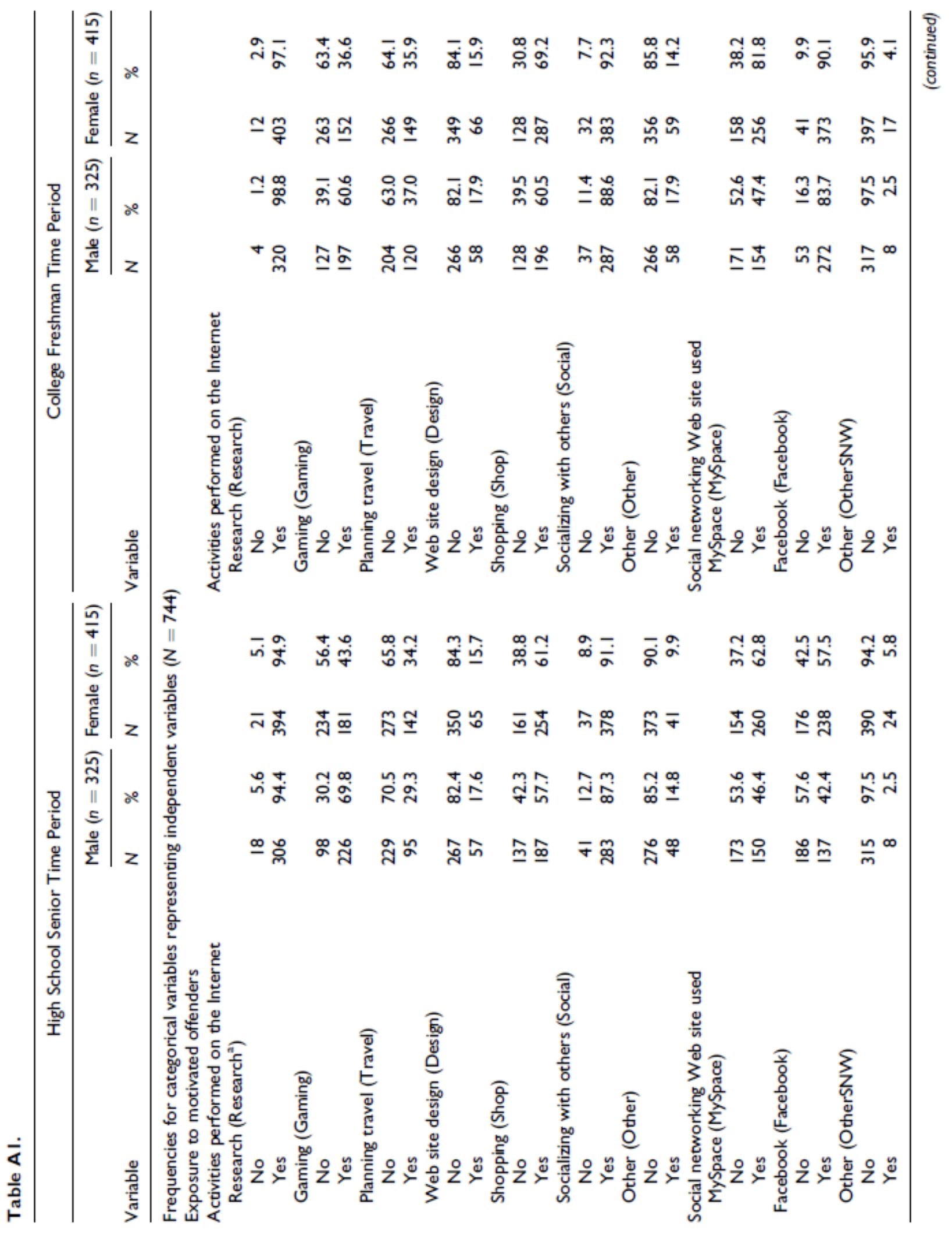




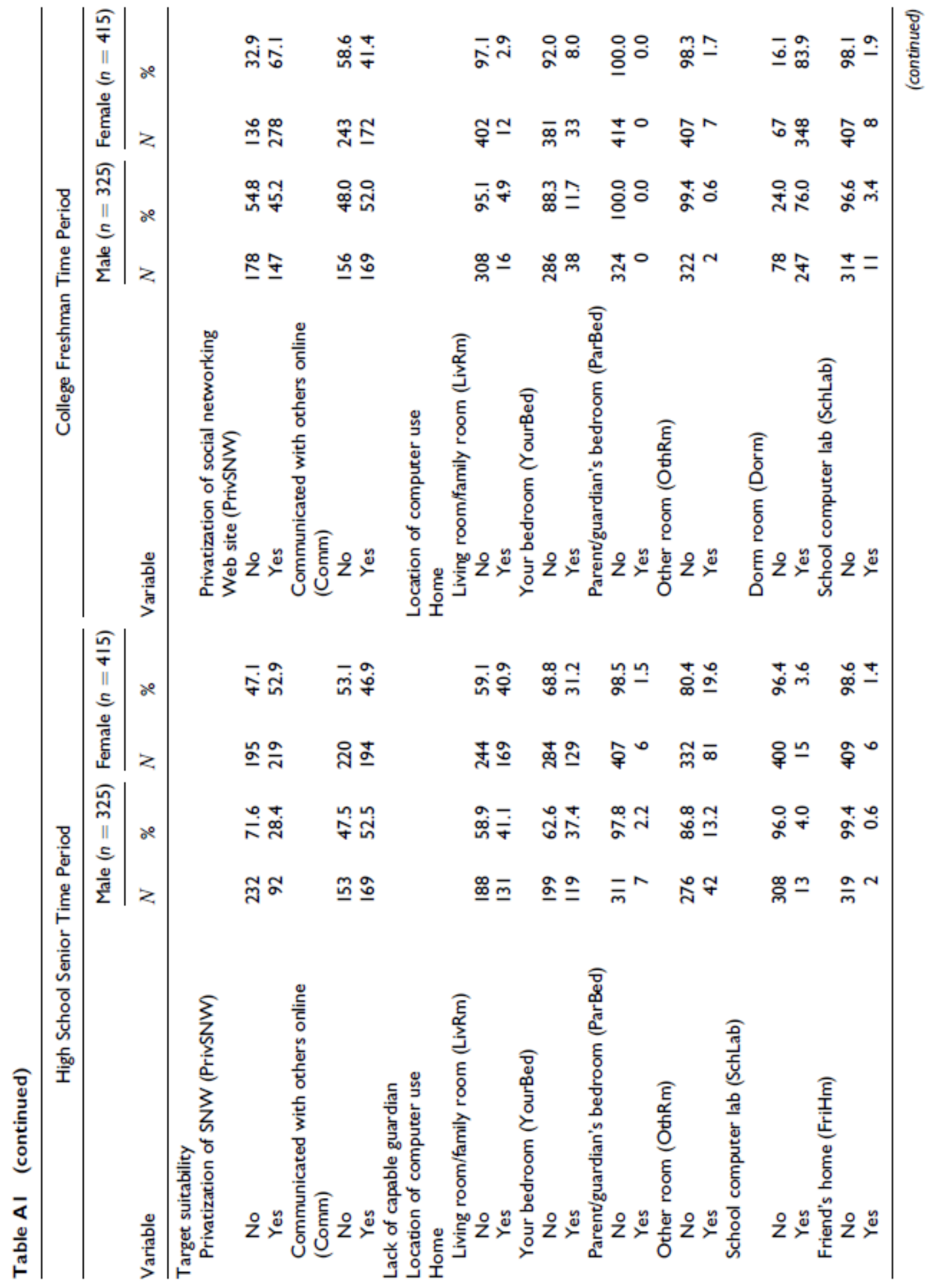




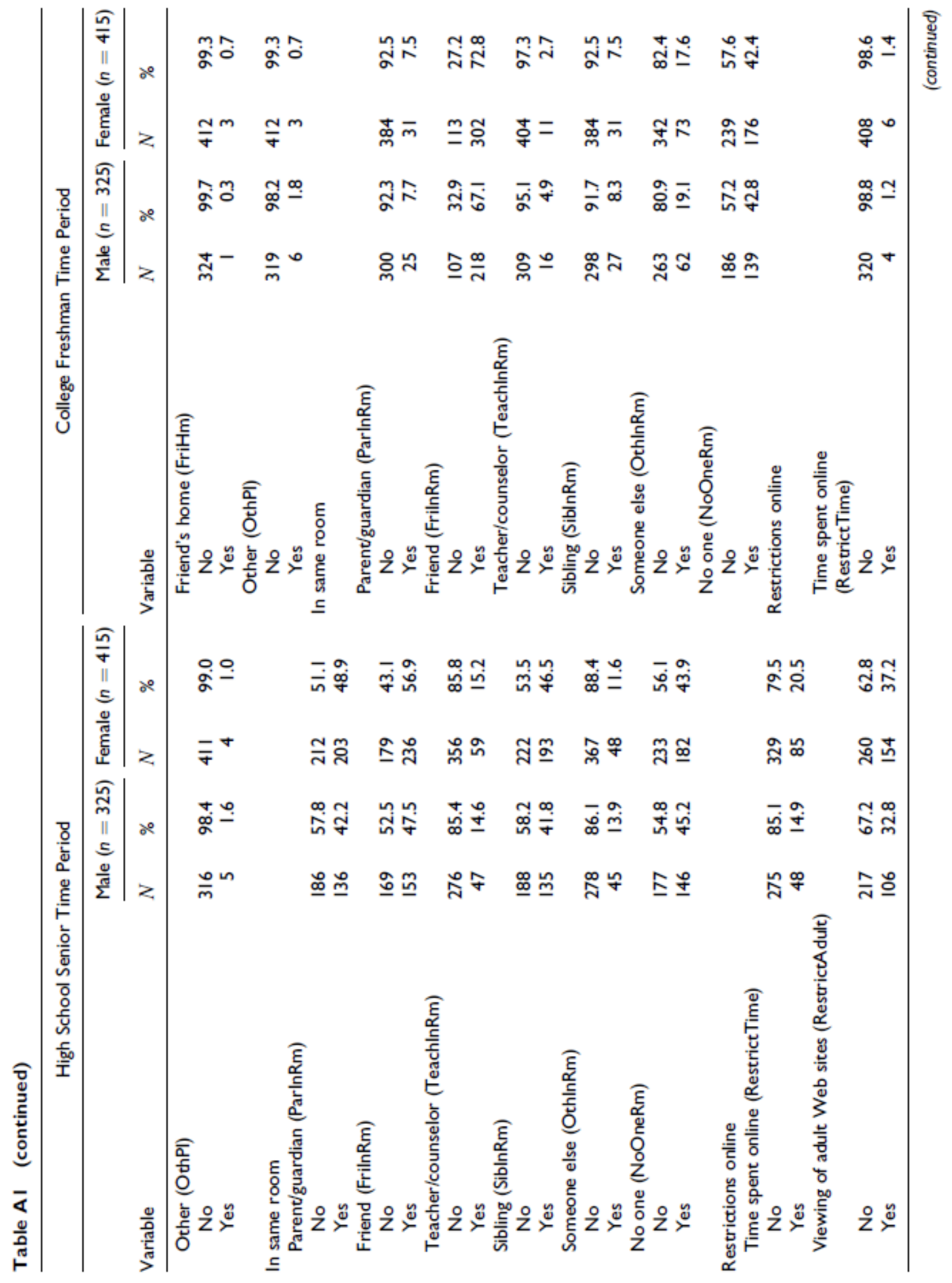




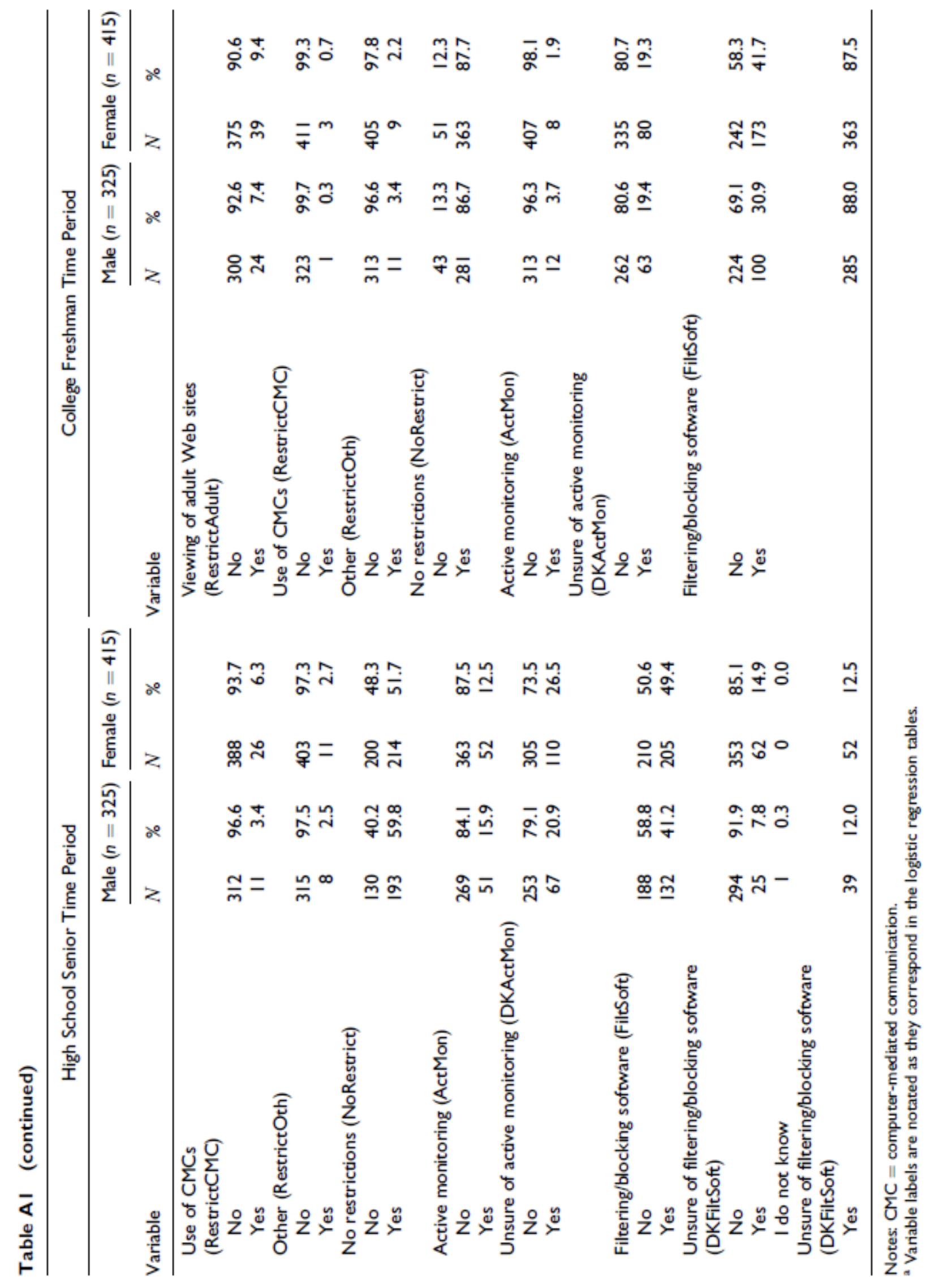




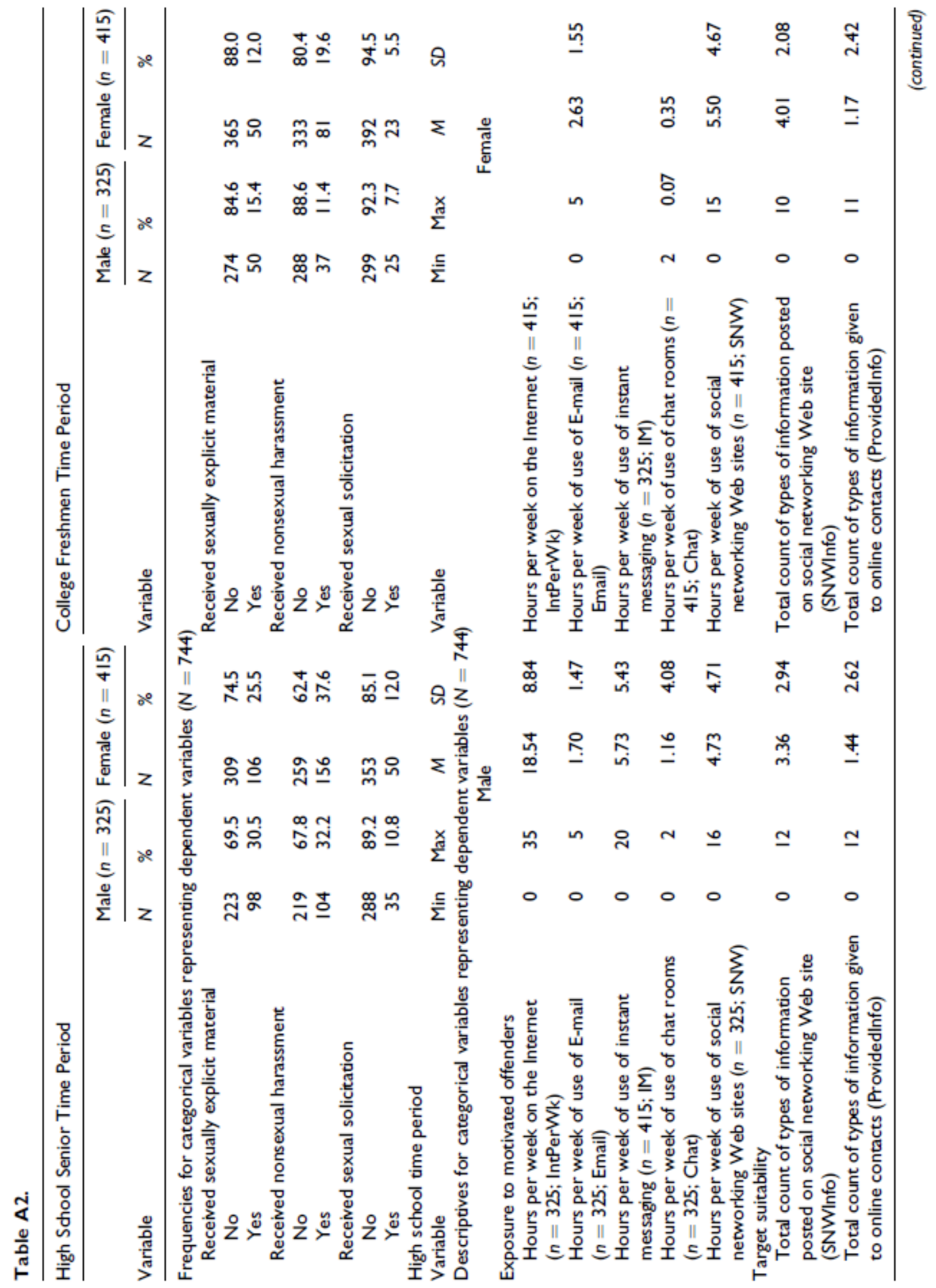




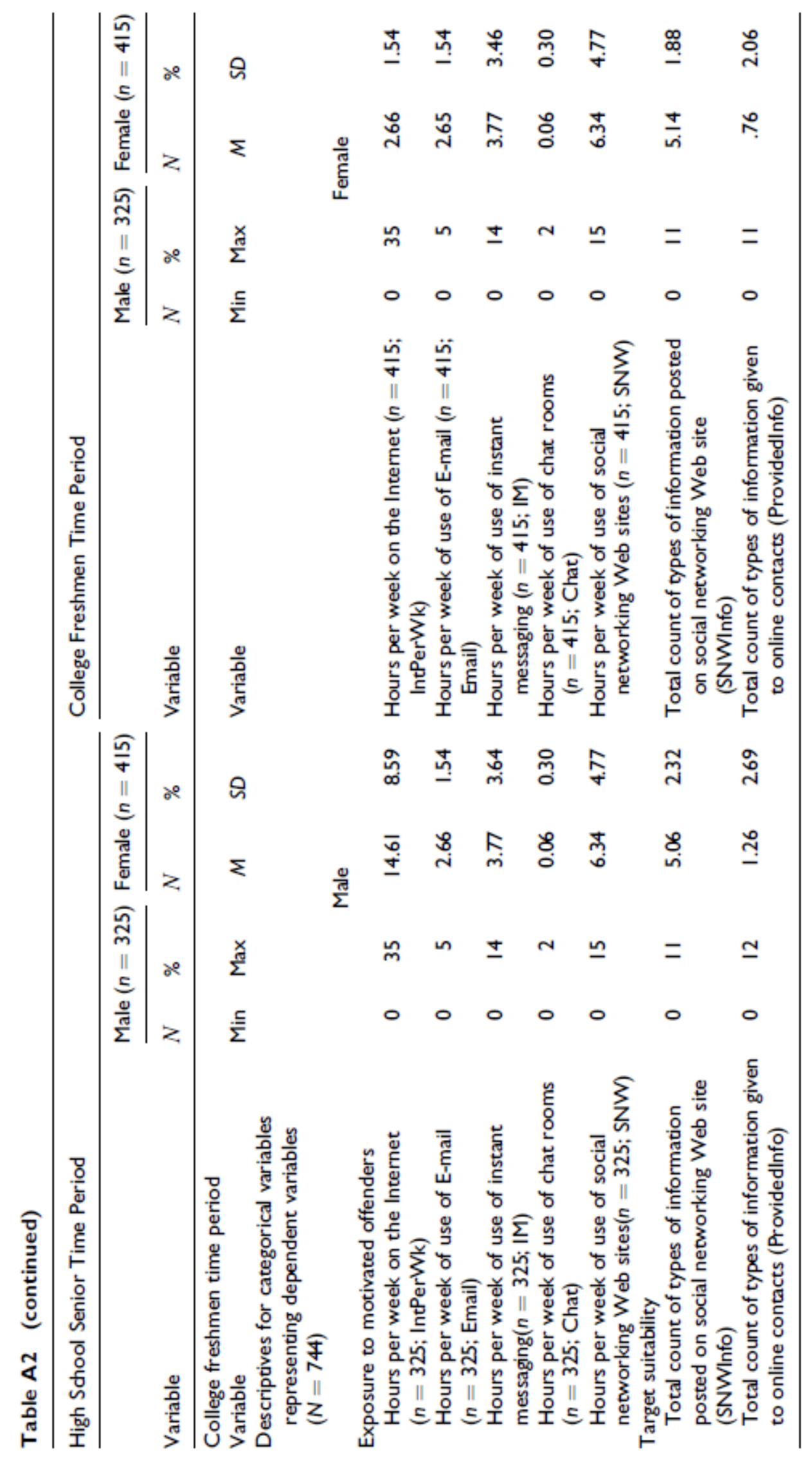


Table A3.

\begin{tabular}{lrrrrr}
\hline Control Variables & \multicolumn{1}{l}{} & & \\
\hline Variable & $N$ & $\%$ & Variable & $N$ & $\%$ \\
\hline Sex (Sex) & & & Age (Age) & & \\
Male & 325 & 43.9 & 18 & 258 & 35.1 \\
Female & 415 & 56.1 & 19 & 289 & 39.3 \\
& & & 20 & 77 & 10.5 \\
& & & 21 and up & 116 & 15.1 \\
Race (Race) & & & Living situation (LivingSituation) & & \\
White & 613 & 82.9 & & & \\
White Hispanic & 22 & 3.0 & & & \\
American Indian/Alaska Native & 3 & 0.4 & Parent/guardian & 11.2 \\
African American & 56 & 7.6 & Other family member & 4 & 0.5 \\
Other & 28 & 3.8 & Dorm & 470 & 63.6 \\
& & & Rented apartment/house & 163 & 22.1 \\
& & & Fraternity/sorority house & 4 & 0.5 \\
& & & Other & 15 & 2.0 \\
\hline
\end{tabular}

\section{REFERENCES}

Addison, D. (2001). Youngsters increase time online as sites seek return visits. Marketing, 10.

Agresti, A., \& Finlay, B. (1997). Statistical methods for the social sciences (3rd ed.). Upper Saddle River, NJ: Prentice Hall.

Arnold, R., Keane, C., \& Baron, S. (2005). Assessing risk of victimization through epidemiological concepts: An alternative analytic strategy applied to routine activities theory. Canadian Review of Sociology and Anthropology, 423, 345-364.

Bendel, R., \& Afifi, A. (1977). Comparison of stopping rules in forward regression. Journal of the American Statistical Association, 72, 46-53.

Bernburg, J., \& Thorlindsson, T. (2001). Routine activities in social context: A closer look at the role of opportunity in deviant behavior. Justice Quarterly, 18, 543-567.

Brantingham, P., \& Brantingham, P. (1981). Environmental criminology. Beverly Hills, CA: SAGE.

Cao, L., \& Maume, D. (1993). Urbanization, inequality, lifestyles and robbery: A comprehensive model. Sociological Focus, 26, 11-26.

Clemmitt, M. (2006). Cyber socializing. CQ Researcher, 16, 1-34.

Cohen, L., \& Cantor, D. (1980). The determinants of larceny: An empirical and theoretical study. Journal of Research in Crime and Delinquency, 17, 140-159.

Cohen, L., \& Felson, M. (1979). Social change and crime rate trends: A Routine Activity Approach. American Sociological Review, 44, 588-608.

Cohen, L., \& Felson, M. (1981). Modeling crime trends: A criminal opportunity perspective. Journal of Research in Crime and Delinquency, 18, 138-164.

Felson, M. (1986). Linking criminal choices, routine activities, informal social control, and criminal outcomes. In D. Cornish \& R. Clarke (Eds.), The reasoning criminal (pp. 119-128). New York: Springer-Verlag. 
Finn, J. (2004). A survey of online harassment at a university campus. Journal of Interpersonal Violence, 19, 468-483.

Forde, D., \& Kennedy, L. (1997). Risky lifestyles, routine activities, and the general theory of crime. Justice Quarterly, 14, 265-289.

Gaetz, S. (2004). Safe streets for whom? Homeless youth, social exclusion, and criminal victimization. Canadian Journal of Criminology and Criminal Justice, 46, 423-455.

Garofalo, J., \& Clark, D. (1992). Guardianship and residential burglary. Justice Quarterly, 9, 443-463.

Giedd, J., Blumenthal, J., Jeffries, N., Castellanos, F., Liu, H., Zijdenbos, A., et al. (1999). Brain development during childhood and adolescence: A longitudinal MRI study. Nature Neuroscience, 2, 861-863.

Greenwood, B. (2009). Pew repots: Internet age barrier vanishing. Information Today. Retrieved October 10, 2009, from http://www.infotoday.com

Hair, J. F., Anderson, R. E., Tatham, R. L., \& Black, W. C. (1998). Multivariate data analysis (5th ed.). Upper Saddle River, NJ: Prentice Hall.

Harris Interactive. (2001). Presenting: The class of 2001. Retrieved September 2, 2005, from http://www. harrisinteractive.com/news/allnewsbydate.asp?NewsID=292

Hawley, A. (1950). Human ecology. New York: The Ronald Press Company.

Hindelang, M., Gottfredson, M., \& Garofalo, J. (1978). Victims of personal crime: An empirical foundation for a theory of personal victimization. Cambridge, MA: Ballinger.

Holt, T., \& Bossler, A. (2009). Examining the applicability of lifestyle-routine activities theory for cyber crime victimization. Deviant Behavior, 30, 1-25.

Hunley, S., Evans, J., Delgado-Hachey, M., Krise, J., Rich, T., \& Schell, C. (2005). Adolescent computer use and academic achievement. Adolescence, 40, 307-318.

Jones, S. (1999). Doing Internet research. London: SAGE.

Jones, S., \& Fox, S. (2009). Generations online in 2009. Pew Internet \& American Life Project. Retrieved June 12, 2009, from http://www.pewinternet.org/Reports/2009/Generations-Online-in-2009.aspx Kendall, V. (1998). The lost child: Congress's inability to protect our teenagers. Northwestern University Law Review, 92, 1307-1315.

Kirkpatrick, M. (2006, May 17). Top 10 social networking sites see 47 percent growth. Thesocialsoftwareweblog. Retrieved September 25, 2006, from http://socialsoftware.weblogsinc.com

LaGrange, T. (1999). The impact of neighborhoods, schools, and malls on the spatial distribution of property damage. Journal of Research in Crime and Delinquency, 36, 393-422.

Lamb, A., \& Johnson, L. (2006). Want to be my friend? What you need to know about social technologies. Teacher Librarian, 34, 55-57.

Leiner, B., Cerf, V., Clark, D., Kahn, R., Kleinrock, L., Lynch, D., et al. (2003). A brief history of the Internet. Internet Society. Retrieved September 24, 2006, from http://www.isoc.org/internet/history/brief.shtml

Lenhart, A., Rainie, L., \& Lewis, O. (2001). Teenage life online: The rise of the instant-message generation and the internet's impact on friendships and family relationships. Washington, DC: Pew Internet \& American Life Project. Retrieved September 25, 2006, from www.pewinternet.org/reports/toc.asp?Report=36 Lin, C., \& Yu, S. (2008). Adolescent Internet usage in Taiwan: Exploring gender differences. Adolescence, 43, 317-331.

Lwin, M., Stanaland, A., \& Miyazaki, A. (2008). Protecting children's privacy online: How parental mediation strategies affect website safeguard effectiveness. Journal of Retailing, 84, 205-217. 
Madriz, E. (1996). The perception of risk in the workplace: A test of routine activity theory. Journal of Criminal Justice, 24, 407-412.

Marcum, C. D. (IN PRESS). Adolescent online victimization: Comparing genders through a test of routine activities theory. Journal of Criminal Justice and Popular Culture.

Medaris, M., \& Girouard, C. (2002). Protecting children in cyberspace: The ICAC task force program. Washington, DC: National Center for Missing \& Exploited Children.

Meier, R., \& Miethe, T. (1993). Understanding theories of criminal victimization. In M. Tonry (Ed.), Crime and justice: An annual review of research (pp. 459-499). University of Chicago Press.

Menard, S. (2007). Applied logistic regression analysis (2nd ed.). Thousand Oaks, CA: SAGE.

Messner, S., \& Tardiff, K. (1985). The social ecology of urban homicide: An application of the routine activities approach. Criminology, 23, 241-267.

Meyers, L., Gamst, G., \& Guarino, A. (2005). Applied multivariate research: Design and interpretation. Thousand Oaks, CA: SAGE.

Mitchell, K., Finkelhor, D., \& Becker-Blease, K. (2007). Classification of adults with problematic Internet experiences: Linking Internet and conventional problems from a clinical perspective. CyberPsychology \& Behavior, 10, 381-392.

Mitchell, K., Finkelhor, D., \& Wolak, J. (2003). The exposure of youth to unwanted sexual material on the Internet: A national survey of risk, impact and prevention. Youth and Society, 34, 300-358.

Mitchell, K., Finkelhor, D., \& Wolak, J. (2007). Youth Internet users at risk for the more serious online sexual solicitations. American Journal of Preventative Medicine, 32, 532-537.

Mottram, A., \& Fleming, M. (2009). Extraversion, impulsivity, and online group membership as predictors of problematic Internet use. CyberPsychology \& Behavior, 12, 319-321.

Mustaine, E., \& Tewksbury, R. (1999). A routine activities theory explanation for women's stalking victimization. Violence Against Women, 5, 43-62.

Nie, N., \& Erbring, L. (2000). Internet and society: A preliminary report. Stanford Institute for the Quantitative Study of Society.

O'Connell, R., Barrow, C., \& Sange, S. (2002). Young peoples use of chat rooms: Implications for policy strategies and programs of education. Retrieved November 1, 2005, from http://www.uclan.ac.uk/host/cru/ publications.htm

Quayle, E., \& Taylor, M. (2003). Model of problematic internet use in people with a sexual interest in children. CyberPsychology \& Behavior, 6, 93-106.

Rainie, L. (2006). Life online: Teens and technology and the world to come. Speech to the annual conference of the Public Library Association, Boston. Retrieved October 1, 2006, from www.pewinternet.org/ppt/ Teens\%20and\%20technology.pdf

Roberts, D., Foehr, U., Rideout, V., \& Brodie, M. (1999). Kids and media @ the new millennium: A comprehensive analysis of children's media use. Menlo Park, CA: The Henry J. Kaiser Family Foundation.

Roncek, D., \& Bell, R. (1981). Bars, blocks, and crimes. Journal of Environmental Systems, 11, 35-47.

Roncek, D., \& Maier, P. (1991). Bars, blocks, and crimes revisited: Linking the theory of routine activities to the empiricism of "hot spots." Criminology, 29, 725-753.

Rosen, L. (2006). Adolescents in MySpace: Identity formation, friendship and sexual predators. Dominguez Hills: California State University. 
Sanger, D., Long, A., Ritzman, M., Stofer, K., \& Davis, C. (2004). Opinions of female juvenile delinquents about their interactions in chat rooms. Journal of Correctional Education, 55, 120-131.

Sasse, S. (2005). "Motivation" and routine activities theory. Deviant Behavior, 26, 547-570.

Schreck, C., \& Fisher, B. (2004). Specifying the influence of the family and peers on violent and victimization. Journal of Interpersonal Violence, 19, 1021-1041.

Schwartz, M., DeKeseredy, W., Tait, D., \& Alvi, S. (2001). Male peer support and a feminist routine activities theory: Understanding sexual assault on the college campus. Justice Quarterly, 18, 623-649.

Simon, J. (2006). Computer-mediated communication: Task performance and satisfaction. Journal of Social Psychology, 146, 349-379.

Spano, R., \& Nagy, S. (2005). Social guardianship and social isolation: An application and extension of lifestyle/ routine activities theory to rural adolescents. Rural Sociology, 70, 414-437.

Steinberg, L. (2004). Risking-taking in adolescence: What changes, and why? Annals of the New York Academy of Sciences, 1021, 51-58.

Stevens, J. (1992). Applied multivariate statistics for the social sciences (2nd ed.). Hillsdale, NJ: Lawrence Erlbaum.

Stutzman, F. (2006). Social networking on campus. Chapel Hill: University of North Carolina.

Tarbox, K. (2000). Katie.com. New York: Penguin.

Tewksbury, R., \& Mustaine, E. (2000). Routine activities and vandalism: A theoretical and empirical study. Journal of Crime and Justice, 23, 81-110.

Tseloni, A., Wittebrood, K., Farrell, G., \& Pease, K. (2004). Burglary victimization in England and Wales, the United States and the Netherlands. The British Journal of Criminology, 44, 66-91.

Wang, J. (2002). Bank robberies by an Asian gang: An assessment of the routine activities theory. International Journal of Offender Therapy and Comparative Criminology, 46, 555-568.

Wells, M., \& Mitchell, K. (2007). Youth sexual exploitation on the Internet: DSM-IV diagnoses and gender differences in co-occurring mental health issues. Child and Adolescent Social Work Journal, 24, 235-260.

Wolak, J., Mitchell, K., \& Finkelhor, D. (2002). Close online relationships in a national sample of adolescents. Adolescence, 37, 441-455.

Wolak, J., Mitchell, K., \& Finkelhor, D. (2003). Escaping or connecting? Characteristics of youth who form close online relationships. Journal of Adolescent Health, 26, 105-119.

Wolak, J., Mitchell, K., \& Finkelhor, D. (2004). Internet-initiated sex crimes against minors: Implications for prevention based on findings from a national study. Journal of Adolescent Health, 35, 11-20.

Wolak, J., Mitchell, K., \& Finkelhor, D. (2006). Online victimization of children: Five years later. Washington, DC: National Center for Missing and Exploited Children.

Wolak, J., Mitchell, K., \& Finkelhor, D. (2007). Unwanted and wanted exposure to online pornography in a national sample of youth Internet users. Pediatrics, 119, 247-257.

Ybarra, M., Mitchell, K., Finkelhor, D., \& Wolak, J. (2007). Internet prevention messages: Targeting the right online behaviors. Archives of Pediatric and Adolescent Medicine, 161, 138-145. 